\title{
Evaluation of moving an acute psychiatric ward from a psychiatric hospital to a general hospital setting
}

\author{
Neil Rothwell, Pauline McManus and John Higgon
}

\begin{abstract}
This study evaluates the effects of moving an acute psychiatric ward from a psychiatric hosplital to a district general hospltal. A repeated measures design is used covering the three phases of shortly before and after the move and a follow-up 10 months affer the move. Eleven measures were used including daily measures of patient disturbance and staff stress, length of stay, diagnosis and a consumer survey. Overall there was Iltile change from before the move to follow-up. Two second-order variables relating to staff stress did, however, show a clear reduction.
\end{abstract}

The past few decades have seen a general movement of acute psychiatric in-patient facilities from psychiatric hospitals (PHs) to general hospital (GH) settings. There are two major motivations behind this shift; first, $\mathrm{GH}$ psychiatry is seen as an important component of a community care system and a means of solving some of the problems associated with PHs (Walkup, 1994); second, there has been a trend to view psychiatry as a medical speciality, standing side-by-side with other specialities (Lancet, 1938). Scottish Office figures for the years 1993-95 indicate that 31\% of all psychiatric admissions were to $\mathrm{GH}$ units. In the US, more psychiatric in-patient care now takes place in a GH than any other setting (Walkup, 1994). It is rather surprising then that there has been relatively little research evaluating the effects of such a relocation (Mayou, 1989).

In a rare example of a controlled study, Jones et al (1980) compared the four-year outcome for two cohorts of patients with a first admission for schizophrenia. One of the cohorts comprised admissions to a district $\mathrm{GH}$ and the other admissions to a traditional PH. The GH cohort had a significantly shorter stay in hospital and the total cost of care was less. In addition, this group showed a better outcome on a number of measures including work motivation and performance, number of patients needing increased contact with the service, and strain felt by relatives.

In evaluating the significance of the move to GHs, it is important to be aware that a unit's performance can be influenced by a number of factors other than location. For example, Mahadevan \& Forster (1982) discovered a marked difference in the way two GH units operated and concluded operational policy may be more important than location. Similarly, Muijen (1992) points out that staff motivation and level of therapeutic skill are the most consistently reported predictors of client functioning following a psychiatric in-patient episode.

The present study examines the effects of moving an acute psychiatric ward from a $\mathrm{PH}$ to a district $\mathrm{GH}$. This allows the effect of the move to be studied while other factors such as staff, therapeutic programmes and ward policies remain largely unchanged.

\section{The study}

The ward studied was one of two which covered a total catchment area of 145000 people, each ward covering a geographically distinct target population (both wards moved at the same time). The ward admitted male and female patients in the 16-65 age range and the number of beds was 24 before and after the move. The PH ward was a self-contained, two-floored building with many quiet corners. The GH ward has an open-plan layout similar to the hospital's general medical wards.

The study was a before-after design with the addition of a follow-up period to analyse longerterm effects. We collected data over three twomonth phases; a baseline commencing three months before the move, a second phase commencing one month after the move and a follow-up period commencing 10 months after the move. 


\section{Measures}

A major aim was to assess the level of patient disturbance on the ward. The nurse in charge completed a form each evening recording the daily frequency of the following: incidents of selfharm; administration of medication when required; patients under close observation; journeys out of the ward where the patient was escorted by a staff member; patients on pass; and number of staff on duty.

The following data were also collected: selfrated nursing staff stress, as rated at the end of each shift on a 10-point rating scale; the length of stay of each patient resident on the ward during each two-month period; the ICD-9 discharge code of each patient; the number of patients compulsorily detained in hospital each day (the last three items above were collected from medical records); consumer satisfaction as measured by a 27-item, four-point consumer survey covering various aspects of the ward environment and service provided. This was distributed to all patients resident on the ward on a particular day near the end of each phase and the numbers of forms returned in the three phases were 14, 14 and 7 respectively (out of a possible 24).

\section{Statistical analysis}

Each measure was compared across the three phases using analysis of variance. Productmoment correlation was used to examine whether the relationship between different measures changed across the phases.

\section{Findings}

Table 1 summarises the results over the three phases. It can be seen that, between the before and follow-up phases, three variables showed a significant change. First, there was a decrease in the daily mean number of patients with a diagnosis in the category of psychosis (this included the diagnostic categories of schizophrenia (ICD-9 code 295), drug-induced psychosis (292) and other non-organic psychoses (298)). Second, there was an increase in the number of compulsorily detained patients. Both of these showed a significant decrease immediately after the move. Third, the number of nursing staff on duty showed a steady rise over the phases. Two further measures showed a significant reduction after the move which are not sustained at followup; daily frequency of escorted journeys out of the ward and staff stress ratings. Two other measures showed a similar 'dip' after the move which reaches statistical significance only between the after and follow-up phases; mean daily number of patients under close observation and incidents of self-harm. No significant statistical change was evident in the other measures. It is of interest, however, that they all showed the same tendency to 'dip' after the move.

Two second-order effects showed a significant trend. First, the correlation between staff stress on a given day and the following day changed over the three phases. Before the move, this was highly significant $(P=0.001)$ but ceased to be significant after the move and at follow-up. The correlation before the move was itself significantly higher than after the move $(P<0.05)$ or at follow-up $(P<0.05)$. Second, the correlation

Table 1. Comparison of listed variables over the three phases of the study'

\begin{tabular}{|c|c|c|c|c|c|c|c|}
\hline & $\begin{array}{l}\text { Before } \\
\text { move }\end{array}$ & $\begin{array}{l}\text { After } \\
\text { move }\end{array}$ & Follow-up & $\begin{array}{l}\text { Overall } \\
\text { significance }\end{array}$ & $\begin{array}{l}\text { Before v. } \\
\text { affer }\end{array}$ & $\begin{array}{l}\text { After } v \text {. } \\
\text { follow-up? }\end{array}$ & $\begin{array}{l}\text { Before v. } \\
\text { follow-ups }\end{array}$ \\
\hline $\begin{array}{l}\text { Escorted patient journeys out of } \\
\text { ward }\end{array}$ & 2.9 & 1.3 & 4.0 & 0.0001 & * & * & \\
\hline $\begin{array}{l}\text { Patients under close observation } \\
\text { Given doses of medication when } \\
\text { required }\end{array}$ & $\begin{array}{l}1.3 \\
2.6\end{array}$ & $\begin{array}{l}0.8 \\
1.8\end{array}$ & $\begin{array}{l}1.5 \\
2.8\end{array}$ & $\begin{array}{l}0.05 \\
\text { NS }\end{array}$ & & * & \\
\hline Patients diagnosed psychotic & 8.5 & 2.9 & 4.0 & 0.0001 & $*$ & * & * \\
\hline Incidents of self-harm & 0.2 & 0 & 0.6 & 0.05 & & * & \\
\hline Patients compulsorily detained & 3.2 & 1.1 & 6.3 & 0.0001 & * & * & • \\
\hline $\begin{array}{l}\text { Patlents on temporary leave from } \\
\text { ward }\end{array}$ & 3.8 & 2.7 & 3.1 & NS & & & \\
\hline Nurses on duty & 2.8 & 3.1 & 3.7 & 0.001 & & * & * \\
\hline Nurse stress self-rating (mean) & 4.9 & 2.8 & 4.2 & 0.001 & * & * & \\
\hline Length of stay (mean) & 161 & 78 & 159 & NS & & & \\
\hline $\begin{array}{l}\text { Total consumer satisfaction score } \\
\text { (mean) }\end{array}$ & 97.1 & 96.9 & 98.8 & NS & & & \\
\hline
\end{tabular}

1. All variables are daily totals except for the last two which relate to the whole phase.

2. The figures indicate significance levels using analysis of variance to compare all three phases (NS=not significant). 3. The presence of a star in the last three columns indicates a statistical probability of less than 0.05 using the Scheffé post hoc test. 
between staff stress and the number of psychotic patients on the ward was significant before the move $(P=0.009)$ but less so after $(P=0.11)$ and non-significant at follow-up.

\section{Comment}

The great majority of the results demonstrate an absence of change directly associated with the ward move. Three variables did show a change at follow-up: the numbers of psychotic and compulsorily detained patients and nursing staff on duty. It is difficult to see how the change in numbers of psychotic patients may have been affected by the move and it is more likely to be due to random variation. For example, GPs in the area did not use acute psychiatric services in other localities either during or after the move. A similar argument applies to the number of compulsorily detained patients. Furthermore, there was no evidence to support the possibility that greater use would be made of the PH's intensive psychiatric care unit (IPCU) in order to facilitate the transition (the numbers of admissions to the IPCU in the three phases was 12,10 and 16 respectively; if this was happening, an increase, rather than a decrease, would be expected immediately after the move). The increase in nursing staff was not a direct result of the move but a coincidental change resulting from the implementation of Project 2000 nurse training proposals. This required that student nurses were no longer included in the ward's nursing establishment and extra money was made available to increase the establishment to take account of this. Apart from this change, the overall costs of running the ward in the two settings were similar.

A high proportion of variables showed a temporary reduction immediately after the move. It is possible that the variation in the number of psychotic patients on the ward may have causally affected the other variables. However. the only other variable that significantly correlates with the number of psychotic patients is staff stress levels, which tends to discount this possibility. The most likely explanation is that the temporary reduction is a spurious and nonspecific Hawthorne effect resulting from the act of moving.

The 'buffering' effect on staff stress, in terms of decreased carry-over of staff stress from one day to another, and decreased influence of the number of psychotic patients on stress is probably due in part to the increased staffing levels. This is supported by the finding that there was a significant negative correlation between number of staff on duty and mean stress during the follow-up phase $(P<0.05$; this relationship is not apparent in the earlier phases). Another possible reason for the lack of daily carry-over was offered by the nurses themselves. The $\mathrm{PH}$ ward was on two levels with the duty room separated from the patient area. This meant that nurses would come in for a shift and receive a handover report without seeing a client. In contrast, the $\mathrm{GH}$ ward, being based on a general medical layout, had close integration of staff and patient areas for the purposes of observation. This meant that nurses would be more aware of the ward atmosphere on entering and would, therefore, know quickly if a difficult situation from the previous day had been resolved. Hopefully, future design of psychiatric in-patient facilities will achieve an optimum balance between the needs of privacy and integration.

Randomised controlled trials are generally regarded as the ideal form of evaluation of clinical interventions. When the intervention being studied is as complex as in-patient psychiatric treatment, however, it is almost impossible to control all the variables known to affect outcome. The before-after design of the present study enabled the effects of change of location to be studied while other factors remained constant. On the other hand, the design does not allow the parallel comparison over time of separate cohorts of patients in the two environments. We have, therefore, had to limit ourselves to an examination of the ward atmosphere and cannot comment on the effectiveness of the two units in terms of patient outcome.

The results reported here are consistent with the view that the physical location of acute psychiatric services has a relatively minor effect on patient behaviour and perceptions compared with other variables (Mahadevan \& Forster, 1982: Muijen, 1992). A new generation of community-based acute psychiatric facilities are now being evaluated. These typically involve a change of therapeutic policy as well as location (Mosher \& Menn, 1978; Dick et al, 1985; Peck \& Scott, 1990). The results suggest these can be very effective and it will be interesting to see what influence these studies have on future health service planning.

\section{Acknowledgements}

Thanks to Ralph McGuire, Bruce Ferrie and to the staff and patients of Ward 17. St John's Hospital, Livingston.

\section{References}

Dick, P.. CAMERon, L., KoHEN, D., et al (1985) Day and fulltime psychiatric treatment: a controlled comparison British Journal of Psychiatry. 147, 246-250. 
JONES, R., GOLDBERG, G. \& HUGHES, B. (1980) A comparison of two different services treating schizophrenia: a cost benefit approach. Psychological Medicine, 10, 493-505.

LANCET (1938) Psychiatric clinics in general hospital. Lancet, i. 850-851.

MAHADEVAN, S. \& FORSTER, D. P. (1982) Psychiatric units in district general hospitals and traditional mental hospitals: some recent evidence. British Journal of Psychiatry, 140, 160-165.

MAYOU, R. (1989) The history of general hospital psychiatry. British Journal of Psychiatry. 155, 764-776.

MOSHER, L. R. \& MENN, A. Z. (1978) Community residentia treatment for schizophrenia: two-year follow-up. Hospital and Community Psychiatry, 29, 715-723.

MULEN. M. (1992) Community care: an evaluation. In Schizophrenia: An Overview and Practical Handbook (ed. D. J. Kavanagh), pp. 424-438. London: Chapman and Hall.
PECK, E. \& SCOTT. J. (1990) Myth and reality. Health Service Joumal, 100, 365.

WALKUP. J. (1994) The early case for caring for the insane in general hospitals. Hospital and Community Psychiatry. 45. 1224-1228.

*Neil Rothwell, Consultant Clinical Psychologist. Robert Fergusson Unit, Royal Edinburgh Hospital, Morningside Place, Edinburgh EH1O 5HF, formerly St John's Hospital, Livingston; Pauline McManus, Charge Nurse, St John's Hospital and John Higgon, formerly Psychology Assistant, Robert Fergusson Unit

*Correspondence 